Article

\title{
Polymeric Nanoparticles Based on Tyrosine-Modified, Low Molecular Weight Polyethylenimines for siRNA Delivery
}

\author{
Alexander Ewe ${ }^{1} \mathbb{D}$, Sandra Noske ${ }^{1,2}$, Michael Karimov ${ }^{1}$ and Achim Aigner ${ }^{1, *}$ \\ 1 Rudolf-Boehm-Institute for Pharmacology and Toxicology, Faculty of Medicine, Clinical Pharmacology, \\ Leipzig University, 04107 Leipzig, Germany; alexander.ewe@medizin.uni-leipzig.de (A.E.); \\ sandra.noske@medizin.uni-leipzig.de (S.N.); michael.karimov@medizin.uni-leipzig.de (M.K.) \\ 2 Faculty of Chemistry, Technical University Kaiserslautern, 67663 Kaiserslautern, Germany \\ * Correspondence: achim.aigner@medizin.uni-leipzig.de; Tel.: +49-(0)341-9724661
}

Received: 29 September 2019; Accepted: 8 November 2019; Published: 12 November 2019

\begin{abstract}
A major hurdle for exploring RNA interference (RNAi) in a therapeutic setting is still the issue of in vivo delivery of small RNA molecules (siRNAs). The chemical modification of polyethylenimines (PEIs) offers a particularly attractive avenue towards the development of more efficient non-viral delivery systems. Here, we explore tyrosine-modified polyethylenimines with low or very low molecular weight (P2Y, P5Y, P10Y) for siRNA delivery. In comparison to their respective parent PEI, they reveal considerably increased knockdown efficacies and very low cytotoxicity upon tyrosine modification, as determined in different reporter and wildtype cell lines. The delivery of siRNAs targeting the anti-apoptotic oncogene survivin or the serine/threonine-protein kinase PLK1 (polo-like kinase 1; PLK-1) oncogene reveals strong inhibitory effects in vitro. In a therapeutic in vivo setting, profound anti-tumor effects in a prostate carcinoma xenograft mouse model are observed upon systemic application of complexes for survivin or PLK1 knockdown, in the absence of in vivo toxicity. We thus demonstrate the tyrosine-modification of (very) low molecular weight PEIs for generating efficient nanocarriers for siRNA delivery in vitro and in vivo, present data on their physicochemical and biological properties, and show their efficacy as siRNA therapeutic in vivo, in the absence of adverse effects.
\end{abstract}

Keywords: poly(ethylene) imine; PEI; RNA; siRNA delivery; tyrosine-modification; tumor xenograft

\section{Introduction}

The induction of RNA interference (RNAi) by small interfering RNAs (siRNAs) [1] has great potential, allowing for the downregulation of pathophysiologically over-expressed genes on the post-transcriptional level. Since siRNAs can be specifically directed against virtually any target gene, including otherwise "undruggable" genes, they offer novel avenues towards customized therapies against many diseases, for example, the treatment of cancer (see, e.g., [2] for review). Today, siRNAs can be easily designed and chemically synthesized to target a gene of interest in a sequence-specific manner. By harnessing the cellular enzyme machinery, siRNAs are incorporated in the RNA-induced silencing complex (RISC) and, upon activation, the siRNA guide strand binds to its complementary target mRNA, leading to mRNA cleavage, degradation, and thus long-lasting gene knockdown. This is a unique characteristic of RNAi which cannot be achieved with small molecules or anti-sense oligonucleotides [3,4].

While it is thus necessary and sufficient to deliver siRNAs to the cell for inducing RNAi-mediated gene knockdown, the physicochemical properties of siRNAs, i.e., relatively high molecular weight, 
high polyanionic charge density, hydrophilic properties, and their instability/susceptibility to nuclease degradation, largely prevent their use in an unmodified form for therapeutic approaches [5]. Beyond chemical modifications of the siRNA, delivery systems are required [6,7]. Apart from siRNA conjugates specifically suited for liver uptake, a variety of different cationic lipids, polymeric materials, and other nanoscale systems have been developed to adsorb, electrostatically interact with or incorporate siRNA and mediate cellular uptake [8-12]. For in vitro application several compounds have been commercialized as transfection reagents and are able to induce a potent gene knockdown at low siRNA concentrations in cell culture [13]. However, they are generally not suited for in vivo applications and clinical translation is still challenging, and thus require the development of novel delivery systems. On the other hand, the feasibility of siRNA therapeutics has been shown when the first siRNA drug, ONPATTRO ${ }^{\circledR}$ (Patisiran), was approved by the US Food and Drug Administration (FDA) and European Medicines Agency (EMA) in 2018. ONPATTRO ${ }^{\circledR}$ is a lipid-based siRNA nanoparticle designed to downregulate transthyretin in the liver for treatment of the polyneuropathy of hereditary transthyretin-mediated amyloidosis (hATTR) [14,15]. Despite this success, it might be assumed that one delivery platform cannot address all diseases, especially when it comes to target tissues other than the liver [16].

Polymeric reagents are another well studied class of materials for the delivery of nucleic acids (for review, see $[17,18]$ ). A highly investigated cationic polymer is polyethylenimine (PEI), which is able to efficiently deliver nucleic acids in vitro and in vivo. PEIs are available in branched and linear topologies over a wide range of molecular weights $(0.8-100 \mathrm{kDa})$ (for review, see [19,20]). While higher molecular weight PEIs show biological activity but are associated with toxicity, low molecular weight PEIs are more biocompatible but essentially lack transfection efficacy, especially in the case of smaller oligonucleotides like siRNA. Branched PEIs are more efficient for the delivery of siRNA than their linear counterparts [21-23]. Since the commercially available $25 \mathrm{kDa}$ branched PEI shows some efficacy but is also attributed to toxic effects, the lower molecular weight PEI F25-LMW (branched; 4-10 kDa) has been introduced for siRNA delivery in vitro and in vivo [24]. Still, further improvements are warranted and various approaches have been explored to optimize transfection efficacies of low molecular weight PEIs and/or to decrease the toxicity of high molecular weight PEIs. These include the covalent modification of PEI with polyethylene glycol (PEG) [25-27], the cross-linking of small PEIs with hydrolysable linkers, e.g., esters, ketals, or reductive cleavable disulfide groups leading to the reversible formation of higher molecular weights ([28-31]; see [32] for review), the copolymerization/grafting with other polymers like polycaprolactone (PCL), starch or polyvinylalcohol (PVA) [33-35], the modification with lipophilic molecules, e.g., fatty acids, alkanes or cholesterol ([36,37], see [38] for review), or the combination of PEI-based complexes with liposomes [39-42].

The chemical modification of PEI with amino acids offers another very promising approach for nucleic acid delivery in vivo. In previous studies, the grafting of arginine, lysine, or leucine onto PEI showed increased $\beta$-galactosidase activity in tumor-bearing mice upon i.v. injection of modified PEI/pDNA complexes [43]. In another report, a library of twenty amino acids conjugated to a poly(amidoamine) (PAMAM G5) dendrimer was characterized for pDNA delivery in vitro and identified cationic and hydrophobic amino acids as most effective [44]. The triple modification of PAMAM G5 with arginine, histidine, and phenylalanine revealed synergistically enhanced pDNA reporter gene expression in vitro and in vivo as compared to their mono-functionalized derivatives [45]. Amino acid modifications have also been shown to improve the delivery of siRNA. Derivatives of a branched $25 \mathrm{kDa}$ PEI with leucine, tryptophan, phenylalanine, or tyrosine were evaluated in vitro and identified the tyrosine-modified PEI as efficient for siRNA transfection [46]. The same high molecular weight $25 \mathrm{kDa}$ branched PEI modified with $N$-acetyl-leucine was used for the delivery of miR34a, significantly improving bone regeneration in an orthodontic in vivo model [47]. The incorporation of histidine and tyrosine also improved in vitro siRNA transfection efficacy in the case of oligoamino amides, a new class of polymers prepared by solid phase synthesis, and decreased the EG5 mRNA expression upon i.v. injection of siEG5 nanoparticles in tumor bearing mice [48,49]. 
It becomes apparent from these studies that for the successful modification of cationic polymers with amino acids a balanced hydrophobicity and hydrophilicity is of great importance. This may then also allow for exploring lower molecular weight PEIs which are insufficiently active in the unmodified form, especially for the delivery of small nucleic acid molecules like siRNAs, but show significantly improved bioactivities upon introducing modifications. In a recent study, we selected a low molecular $10 \mathrm{kDa}$ branched PEI for tyrosine modification. This new PEI derivative (P10Y) showed excellent in vitro siRNA transfection efficacies and increased complex stability upon serum contact. Moreover, P10Y/siRNA complexes decreased tumor growth in an aggressively growing melanoma xenograft mouse model $[50,51]$. Based on these results, we extended this approach towards even smaller $2 \mathrm{kDa}$ and $5 \mathrm{kDa}$ branched PEIs. Initial data indicated high knockdown efficacies of these small tyrosine-modified derivatives compared to their otherwise inactive parent PEIs [51]. In this study, we comprehensively explore these small tyrosine-PEIs in various cell lines, for targeting different reporter genes as well as endogenous genes. We identify P5Y as particularly active, and thus also studied this most efficient derivative in a tumor xenograft mouse model.

\section{Materials and Methods}

\subsection{Cells and Cell Culture}

Cell culture plastics and consumables were from Sarstedt (Nümbrecht, Germany). Cell culture media were from Sigma-Aldrich (Taufkirchen, Germany) and fetal calf serum was purchased from Biochrom (Berlin, Germany). The cell lines HCT116 (colorectal carcinoma), H441 (lung adenocarcinoma), PC3 (prostate carcinoma), Saos-2 (osteosarcoma), and MV3 (melanoma) were obtained from ATCC/LGC Promochem (Wesel, Germany), and G55T2 (glioblastoma) was a kind gift from Katrin Lamszus (University Clinic Hamburg-Eppendorf, Hamburg, Germany). All cell lines were cultivated in a humid atmosphere at $37^{\circ} \mathrm{C}$ and $5 \% \mathrm{CO}_{2}$. HCT116, PC3, G55T2 cells were grown in IMDM medium, $\mathrm{H} 441$ and MV3 cells were grown in RPMI 1640 medium, and Saos-2 cells were grown in McCoy's 5a medium. All media were supplemented with 10\% FCS and $2 \mathrm{mM}$ alanyl-glutamine.

Reporter cell lines were stably transduced by lentiviral transduction. The EGFP/luciferase plasmid pCCLc-MNDU3-Luciferase-PGK-EGFP-WPRE was a gift from Fernando Fierro (University of California, Davis, CA, USA; Addgene plasmid \# 89608) [52]) and the luciferase plasmid pLenti PGK V5-LUC Puro (w543-1) was a gift from Eric Campeau and Paul Kaufman (University of Massachusetts, Worchester, MA, USA; Addgene plasmid \# 19360) [53]. Cell lines were cultivated in the above mentioned media and stable reporter cells were selected by either using puromycin (luciferase plasmid) or sorted by FACS (EGFP/luciferase plasmid).

\subsection{Synthesis of Tyrosine-Modified PEIs}

Branched polyethylenimines were obtained from the following suppliers: $2 \mathrm{kDa}$ PEI (Sigma-Aldrich, Taufkirchen, Germany), 5 kDa PEI (a kind gift from BASF, Ludwigshafen, Germany), and $10 \mathrm{kDa}$ PEI (Polysciences, Eppelheim, Germany). N-Boc-tyrosine-OH, N-hydroxysuccinimide, EDC. $\mathrm{HCl}$ were from Carbolution Chemicals (Saarbrücken, Germany). Dry N,N-Dimethylformamide (DMF) was from VWR (Darmstadt, Germany), Trifluoroacetic acid (TFA), ethanol, and methanol were from Carl Roth (Karlsruhe, Germany).

For the tyrosine modification, $N$-Boc (tert-butyloxycarbonyl) protected tyrosine $(0.65 \mathrm{~g}, 2.3 \mathrm{mmol})$ and $N$-hydroxysuccinimide $(0.27 \mathrm{~g}, 2.3 \mathrm{mmol})$ were dissolved in $3 \mathrm{~mL}$ dry DMF in a glass vial, followed by addition of EDC. $\mathrm{HCl}(0.45 \mathrm{~g}, 2.3 \mathrm{mmol})$, and stirred for $4 \mathrm{~h}$ under a nitrogen atmosphere at RT. In a second vial, PEI $(0.2 \mathrm{~g}, 4.65 \mathrm{mmol}$ in ethylenimine) was dissolved in $3 \mathrm{~mL}$ dry DMF, and the pre-activated tyrosine mixture was added and further stirred under nitrogen for $3 \mathrm{~d}$. The reaction mixture was purified by dialysis ( $1 \mathrm{kDa}$ MWCO regenerated cellulose, Serva, Heidelberg, Germany) against methanol for $10 \mathrm{~h}$ with intermediate solvent replacement to remove by-products. Next, the methanol was removed in vacuo and the viscous polymer was dissolved in $3 \mathrm{~mL}$ TFA, prior to 
stirring overnight for Boc-deprotection. Excess TFA was removed by co-evaporation with ethanol. Finally, the crude polymer was dissolved in $0.1 \mathrm{M} \mathrm{HCl}$ and excessively purified by dialysis against $0.05 \mathrm{M} \mathrm{HCl}$ for $24 \mathrm{~h}$, then against water for $48 \mathrm{~h}$. Lyophilization yielded the tyrosine-modified PEIs as yellowish fluffy powders. The degree of functionalization ( $25-30 \%$ based on ethylenimine monomer) was confirmed by ${ }^{1} \mathrm{H}-\mathrm{NMR}$ (Mercury plus, $300 \mathrm{MHz}$, Varian Agilent Technologies, Santa Clara, CA, USA) as described previously [50,51].

\subsection{Polyplex Preparation}

The polyplexes were prepared based on polymer/siRNA mass ratios. Typically, the P5Y- and P10Y-based complexes were prepared at a mass ratio of 2.5 unless indicated otherwise. For P2Y, a mass ratio of 10 was used. For standard transfection experiments in a 24 well plate, 30 pmol $(0.4 \mu \mathrm{g})$ siRNA per well was diluted in $12.5 \mu \mathrm{L} \mathrm{HN}$ buffer $(150 \mathrm{mM} \mathrm{NaCl}, 10 \mathrm{mM}$ HEPES (4-(2-hydroxyethyl)-1-piperazineethanesulfonic acid), pH 7.4). In a separate tube, the calculated amount of the polymer was diluted in $12.5 \mu \mathrm{L} \mathrm{HN}$ buffer and the siRNA solution was added to the polymer solution, thoroughly mixed by pipetting up and down and incubated for 30 min at RT. For serum stability studies, the prepared polyplexes were additionally incubated with different volumes of FCS.

For in vivo experiments, the polyplexes were prepared as above, with slight modifications. Per dose for injection, $10 \mu \mathrm{g}$ siRNA was diluted in $75 \mu \mathrm{L} \mathrm{HN}$ buffer and $25 \mu \mathrm{g}$ (mass ratio 2.5) of the polymer (P5Y) was diluted in $75 \mu \mathrm{L} 5 \%(w / v)$ glucose, $10 \mathrm{mM}$ HEPES pH 7.4. The complexation was performed as described above.

\subsection{Polyplex Characterization}

The hydrodynamic diameters and zeta potentials were measured by dynamic light scattering (DLS) and phase analysis light scattering (PALS) with a Brookhaven ZetaPALS system (Brookhaven Instruments, Holtsville, NY, USA). Polyplexes containing $5 \mu \mathrm{g}$ siRNA in $250 \mu \mathrm{L}$ were prepared as described above and diluted to $1.7 \mathrm{~mL}$ with millipore water. The data were analyzed using the manufacturer's software, with applying the viscosity and refractive index of pure water at $25^{\circ} \mathrm{C}$. For the size determination, polyplexes were measured in five runs with a run duration of 1 min per experiment. Zeta potentials were analyzed in ten runs, with each run containing ten cycles using the Smoluchowski model. Additionally, polyplex sizes were analyzed by nanoparticle tracking (NTA) using a NanoSight LM10 (Malvern, Wiltshire, UK) equipped with a $640 \mathrm{~nm}$ sCMOS camera, software NTA 3.0, and a siRNA concentration of $1 \mu \mathrm{g} / \mathrm{mL}$.

Complex stabilities were determined by a heparin displacement assay. The complexes based on the different tyrosine-modified PEIs were prepared at their optimal mass ratios as described above, prior to further incubation in FCS $(50 \%, v / v)$ for $1 \mathrm{~h}$. The complexes were then subjected to the polyanion heparin at different concentrations (units), as indicated in Figure S3C. A total of $25 \mu \mathrm{L}$ of the mixture containing $0.2 \mu \mathrm{g}$ siRNA was analyzed by $1.5 \%$ agarose gel electrophoresis.

\subsection{Cell Transfection}

For standard transfection experiments, the cells were seeded at a density of 35,000 cells per well of a 24 well plate in $0.5 \mathrm{~mL}$ fully supplemented medium. The next day, the cells were transfected with polyplexes containing $30 \mathrm{pmol} / 0.4 \mu \mathrm{g}$ siRNA per 24 well as described above in the presence of FCS and without further medium change. For siRNA targets and sequences see Table S1.

\subsection{Determination of Knockdown Efficacies and Complex Uptake}

Luciferase activities were determined $72 \mathrm{~h}$ after transfection using the Beetle-Juice Kit (PJK, Kleinblittersdorf, Germany). The medium was aspirated and the cells were lysed with $300 \mu \mathrm{L}$ Luciferase Cell Culture Lysis Reagent (Promega, Mannheim, Germany) for 30 min at RT. In a test tube, 
$10 \mu \mathrm{L}$ lysate was mixed with $25 \mu \mathrm{L}$ substrate and the luminescence was immediately measured in a luminometer (Berthold, Bad Wildbad, Germany).

The EGFP expression was determined by flow cytometry after $72 \mathrm{~h}$. The cells were trypsinized, centrifuged for $3 \mathrm{~min}$ at $3000 \mathrm{rpm}$, and resuspended in $0.5 \mathrm{~mL}$ PBS, 1\% BSA. The cells were measured in an Attune ${ }^{\circledR}$ Acoustic Focusing Cytometer (Applied Biosystems, Foster City, CA, USA). Finally, 20,000 events in the vital gate were analyzed using the Attune ${ }^{\circledR}$ software (V2.1.0).

For uptake experiments, complexes were prepared as described above (Section 2.4), but using a fluorophore-labeled siRNA-Atto488. PC3 wildtype cells were transfected, after $24 \mathrm{~h}$ prepared as described above with an additional PBS washing step and analyzed by flow cytometry.

To visualize the complex uptake by confocal microscopy, PC3 wildtype cells were seeded at a density of 200,000 cells onto glass coverslips in a 6 well plate. The next day, the cells were transfected with complexes of the different tyrosine-modified PEIs containing Alexa Fluor ${ }^{\circledR}$ 647-labeled siRNA ( $2 \mu \mathrm{g}$ siRNA/well). After $36 \mathrm{~h}$, the siRNA uptake and intracellular distribution was analyzed by confocal microscopy (TCS SP8, Leica, Wetzlar, Germany).

\subsection{Cell Proliferation and Viability Assays}

For proliferation assays, cells were seeded at a density of 2000 cells (PC3 and Saos-2) or 1000 cells (MV3) per well of a 96 well plate in $100 \mu \mathrm{L}$ medium on the day before transfection. For endpoint cell viability assays, PC 3 or G55T2 cells were seeded at a density of 7000 cells per 96 well in $100 \mu \mathrm{L}$ medium. The number of metabolically active cells after transfection was determined by using a colorimetric assay (WST-8 Cell Counting Kit-8; Dojindo Molecular Technologies EU, Munich, Germany). Briefly, after aspirating the medium, $50 \mu \mathrm{L}$ of a 1:10 dilution of WST-8 in serum-free medium was added to the cells and incubated at $37^{\circ} \mathrm{C}$ for $1 \mathrm{~h}$. The absorbance was measured at $450 / 620 \mathrm{~nm}$ in a plate reader.

Acute cell damage caused by the polyplexes was determined by measuring the extent of lactate dehydrogenase (LDH) release, using the Cytotoxicity Detection Kit (Roche, Mannheim, Germany) according to the manufacturer's manual. Briefly, conditioned medium from transfection experiments (negative control siRNA) was collected after $24 \mathrm{~h}$. For the determination of the maximum LDH release, cells were lysed with Triton X-100 at a final concentration of $2 \%$, and conditioned medium from untreated cells served as negative control. In a 96 well plate, $50 \mu \mathrm{L}$ sample medium was mixed with $50 \mu \mathrm{L}$ reagent mix and incubated for $30 \mathrm{~min}$ in the dark. The reaction was stopped with $50 \mu \mathrm{L} 1 \mathrm{M}$ acetic acid and the absorption at $490 / 620 \mathrm{~nm}$ was measured using a plate reader. For blank value correction, fresh fully supplemented medium was mixed with the reagent and subtracted from all values.

\subsection{RNA Preparation and Quantitative RT-PCR (RT-qPCR)}

Total RNA was isolated using a combined TRI reagent and silica column protocol. Per 24 well, cells were lysed in $500 \mu \mathrm{L}$ TRI reagent (TriFast, VWR, Darmstadt, Germany) and incubated for 5 min at RT. The lysate was transferred into a $1.5 \mathrm{~mL}$ tube and $200 \mu \mathrm{L}$ chloroform was added, mixed well by shaking and incubated for $5 \mathrm{~min}$ at RT. The samples were centrifuged at 12,000 $\mathrm{g}$ for $15 \mathrm{~min}$ and the upper aqueous phase $(\sim 300 \mu \mathrm{L})$ was pipetted into a new $1.5 \mathrm{~mL}$ tube containing $300 \mu \mathrm{L} 100 \%$ ethanol. After mixing, the sample was loaded onto the column (Zymo-Spin IC, Zymo Research, Freiburg, Germany), prior to centrifugation at $8000 \mathrm{~g}$ for $1 \mathrm{~min}$. The flow-through was discarded. The column was washed twice with $450 \mu \mathrm{L} 3 \mathrm{M}$ sodium acetate $\mathrm{pH}$ 5.2, and once with $70 \%$ ethanol by centrifugation at $8000 \mathrm{~g}$ for $1 \mathrm{~min}$; the collection tube was emptied after each step. For the drying step, the collection tube was replaced by a new one, and the columns were centrifuged at 12,000 $\mathrm{g}$ for $2 \mathrm{~min}$. For RNA elution, $15 \mu \mathrm{L}$ DEPC-water, pre-warmed to $65^{\circ} \mathrm{C}$, was added onto the column and incubated for $2 \mathrm{~min}$, before finally eluting the RNA by centrifugation at $8000 \mathrm{~g}$ for $2 \mathrm{~min}$. RNA concentrations and purities were measured in a NanoDrop 2000c (Thermo Fisher, Schwerte, Germany).

The total RNA was reverse transcribed with the RevertAid ${ }^{\mathrm{TM}} \mathrm{H}$ Minus First strand cDNA synthesis Kit (Thermo Fisher, Waltham, MA, USA). In brief, $1 \mu \mathrm{L}$ random hexamer primer was added to $1 \mu \mathrm{g}$ RNA diluted in $10 \mu \mathrm{L}$ DEPC-treated water, followed by an incubation step for $5 \mathrm{~min}$ at $65^{\circ} \mathrm{C}$ and 
cooling to $4{ }^{\circ} \mathrm{C}$. Then, $4 \mu \mathrm{L} 5 \times$ reaction buffer, $2 \mu \mathrm{L} 10 \mathrm{mM}$ dNTP mix, $2.5 \mu \mathrm{L}$ DEPC-treated $\mathrm{ddH}_{2} \mathrm{O}$, and $0.5 \mu \mathrm{L}$ RevertAid ${ }^{\mathrm{TM}} \mathrm{H}$ Minus M-MuLV Reverse Transcriptase $(200 \mathrm{U} / \mu \mathrm{L})$ were added. The cDNA synthesis mixture was incubated at $25^{\circ} \mathrm{C}$ for $10 \mathrm{~min}, 42^{\circ} \mathrm{C}$ for $60 \mathrm{~min}$, and heat denatured at $70{ }^{\circ} \mathrm{C}$ for $10 \mathrm{~min}$.

For quantitative real time PCR, a StepOnePLUS Real-Time PCR System (Applied Biosystems, Foster City, CA, USA) was used, applying the $\Delta \Delta \mathrm{Ct}$ method [54]. The cDNA was 1:10 diluted with DEPC-water and $4 \mu \mathrm{L}$ were mixed with $5 \mu \mathrm{L} 2 x$ PerfeCTa SYBR ${ }^{\circledR}$ Green FastMix ROX (Quantabio, Beverly, MA, USA) and $1 \mu \mathrm{L} 5 \mu \mathrm{M}$ forward and reverse primer mix (see Table S2 for primer sequences). The qPCR were run with a pre-incubation at $95^{\circ} \mathrm{C}$ for $2 \mathrm{~min}$, followed by 45 amplification cycles $\left(95^{\circ} \mathrm{C}\right.$ for $15 \mathrm{~s}, 55^{\circ} \mathrm{C}$ for $\left.15 \mathrm{~s}, 72{ }^{\circ} \mathrm{C} 15 \mathrm{~s}\right)$.

\subsection{Hemolysis}

To determine the hemolytic activity of the complexes, whole blood from healthy mice was diluted in Ringer's solution and erythrocytes were purified by several centrifugation and washing steps at $5000 \mathrm{rpm}$ for $5 \mathrm{~min}$, until the supernatant became clear. After the final washing step, the cells were taken up into physiological $\mathrm{NaCl}$ solution. Then, $1 \times 10^{6}$ cells in $50 \mu \mathrm{L}$ were mixed with $50 \mu \mathrm{L}$ complexes containing different siRNA amounts and incubated for $1 \mathrm{~h}$ at $37^{\circ} \mathrm{C}$. For absorption measurements, $25 \mu \mathrm{L}$ of each sample were transferred into a 96 well plate in triplicates. Erythrocytes incubated with buffer served as negative control and erythrocytes treated with Triton X-100 to a final concentration of $1 \%$ served as positive control $(=100 \%)$. The absorbance of the samples was measured at $550 \mathrm{~nm}$ using a plate reader.

To evaluate erythrocyte aggregation, $50 \mu \mathrm{L}$ of the purified cells $\left(\sim 1 \times 10^{6}\right.$ cells $\left./ \mathrm{mL}\right)$ were mixed with $50 \mu \mathrm{L}$ aqueous solution containing $7.5 \mu \mathrm{g}$ P5Y/3 $\mu \mathrm{g}$ siCtrl, or $750 \mathrm{kDa}$ branched PEI ( 1 and $3 \mu \mathrm{g})$ as positive control. After incubation for $2 \mathrm{~h}$ at $37^{\circ} \mathrm{C}$, the samples were mounted onto glass slides and examined microscopically.

\subsection{In Vivo Tumor Therapy}

Athymic nude mice (Foxn1nu, Charles River Laboratories, Sulzfeld, Germany) were kept at $23^{\circ} \mathrm{C}$ in a humidified atmosphere, $12 \mathrm{~h} \mathrm{light/dark} \mathrm{cycle,} \mathrm{with} \mathrm{standard} \mathrm{rodent} \mathrm{chow} \mathrm{and} \mathrm{water} \mathrm{ad}$ libitum. Animal studies were performed according to the national regulations and approved by the local authorities (Landesdirektion Sachsen, approval NO. TVV 38/16, date: 20 January 2017). Tumor xenografts were established by injecting $3 \times 10^{6}$ PC 3 cells in $150 \mu \mathrm{L}$ PBS subcutaneously (s.c.) into both flanks of mice. When tumors reached a size of $\sim 100 \mathrm{~mm}^{3}$, the mice were randomized into different treatment groups (6-9 tumors/group). The polyplexes were prepared as described above and amounts corresponding to $10 \mu \mathrm{g}$ siRNA were i.p. injected every 2-3 days over 14 days.

For in vivo luciferase knockdown experiments, $3 \times 10^{6}$ HCT116-Luc cells were s.c. injected for the induction of tumor xenografts described above. Mice were treated five times every 2-3 days with P5Y/siRNA complexes (siLuc2 = siCtrl and siLuc3 = Luciferase specific siRNA). Tumors were excised and lysed with Luciferase Cell Culture Lysis Reagent (app. $100 \mathrm{mg}$ tumor tissue/1 mL buffer), prior to homogenization using an ULTRA-TURRA ${ }^{\circledR}$. Homogenates were repeatedly centrifuged at $13,000 \mathrm{rpm}$ for $5 \mathrm{~min}$ and the supernatants were transferred into fresh tubes until the lysate became clear. Luminescence was determined as described above. Relative light units (RLU) were normalized for total protein concentration of the lysates using the BCA assay (Pierce Thermo Fisher, Schwerte, Germany) according to the manufacturer's protocol.

For the determination of blood serum markers, healthy nude mice were i.p. injected with P5Y/siLuc3 complexes containing $10 \mu \mathrm{g}$ siRNA every 2-3 days, with a total of four times over 8 days. Three hours after the last injection, the blood was collected. Untreated mice served as negative control. The serum was diluted 1:20 with water and serum levels of various analytes were determined using an AU480 (Beckman Coulter, Krefeld, Germany). 
For the analysis of the immunostimulatory cytokines TNF- $\alpha$ and INF- $\gamma$, P5Y/siLuc3 complexes (10 $\mu \mathrm{g}$ siRNA) were i.v. injected twice within $24 \mathrm{~h}$ into immunocompetent C57BL/6 mice. Four hours after the last injection, the blood was collected. Mice treated with lipopolysaccharides (LPS) $50 \mu \mathrm{g}$ in $150 \mu \mathrm{L}$ (single injection) served as positive control and untreated mice served as negative control. The serum levels of TNF- $\alpha$ and INF- $\gamma$ were measured using ELISA kits (PreproTech, Hamburg, Germany) following the manufacturer's instructions.

\subsection{Statistics}

Statistical analyses were performed by Student's $t$-test or One-way ANOVA, and significance levels are ${ }^{*}=p<0.05,{ }^{* *}=p<0.01,{ }^{* * *}=p<0.001$, and $\#=$ not significant, with at least $n=3$.

\section{Results}

\subsection{Identification of Optimal Complexes for In Vitro Transfection}

Based on the superior siRNA complexation and transfection efficacy of $10 \mathrm{kDa}$ PEI upon its tyrosine-modification, we analyzed the performance of even smaller PEIs, which had been shown previously to be inactive [51], upon tyrosine engraftment. We hypothesized that even in the case of $5 \mathrm{kDa}$ or $2 \mathrm{kDa}$ PEIs, the tyrosine modification may result in polymers capable of efficient siRNA complexation and delivery, thus leading to target gene knockdown and RNAi-mediated tumor cell-inhibitory effects in various cellular assays. The tyrosine was covalently coupled onto branched PEIs by using standard NHS/EDC coupling chemistry as outlined in Figure 1A. The degree of tyrosine modification was $\sim 30 \%$ compared to ethylenimine monomers, determined by ${ }^{1} \mathrm{H}-\mathrm{NMR}$ analysis as described $([50,51]$; see Figure S1). Transfection experiments with complexes based on the tyrosine-modified $5 \mathrm{kDa}$ PEI (P5Y) revealed $>90 \%$ knockdown of serine/threonine-protein kinase PLK1 (polo-like kinase 1; PLK-1) when transfecting a specific siPLK1 as compared to a negative control siRNA (siCtrl; Figure 1B, left). Complexes based on P10Y or P5Y were even more efficient than their higher molecular weight $25 \mathrm{kDa}$ counterpart (P25Y; data not shown), while P2Y/siRNA complexes comprising the very low molecular weight $2 \mathrm{kDa}$ PEI were less efficient. Similar results were obtained after transfection of an siRNA targeting the anti-apoptotic protein survivin, with P5Y/siRNA and P10Y/siRNA complexes again resulting in a $80-90 \%$ knockdown (Figure 1B, right) and thus performing better than their P25Y/siRNA counterparts (not shown). P2Y-based nanoparticles showed somewhat reduced activity, even when using higher N/P ratios. The knockdown of the oncogenes/proto-oncogenes PLK-1 and survivin also exerted profound tumor cell-inhibitory effects in anchorage-dependent proliferation assays (Figure 1C). When using P5Y or P10Y, the transfection of 6 pmol/well siRNA was sufficient to largely abolish cell proliferation. In contrast, in the case of P2Y/siRNA complexes, even double amounts (12 pmol) were incapable of inhibiting cell growth. Only the transfection of a very potent ubiquitin siRNA, which essentially abolished tumor cell viabilities in the P5Y and P10Y transfection groups, was strong enough to partially inhibit cell growth when complexed with P2Y. For the very efficient P10Y and P5Y, the siRNA concentration could be further reduced to 3 pmol siRNA with still showing strong inhibitory effects (Figure S2A). In addition, this reduction revealed differences in the potencies of the siRNAs against different target genes. 
A

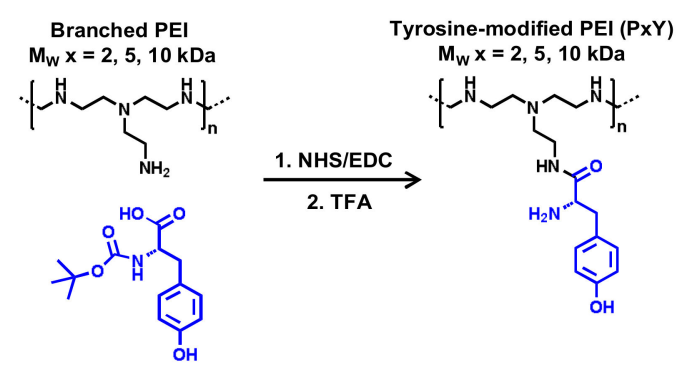

B

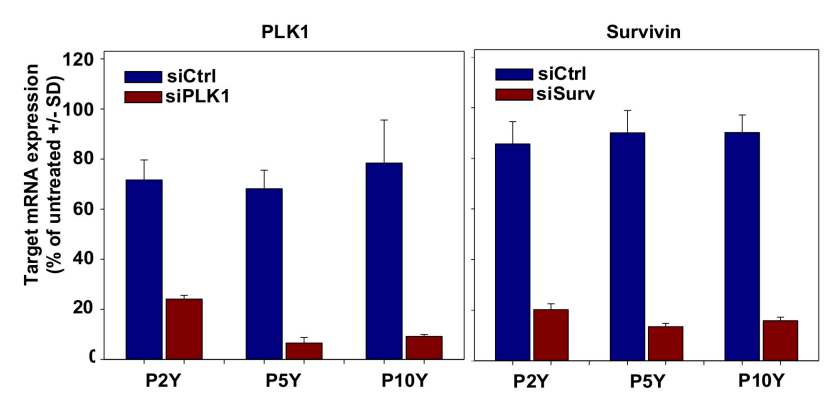

D

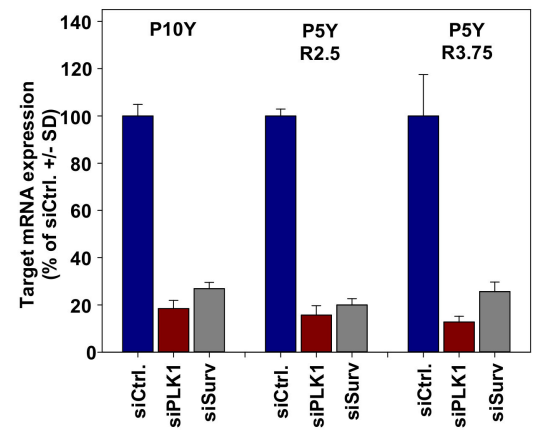

C
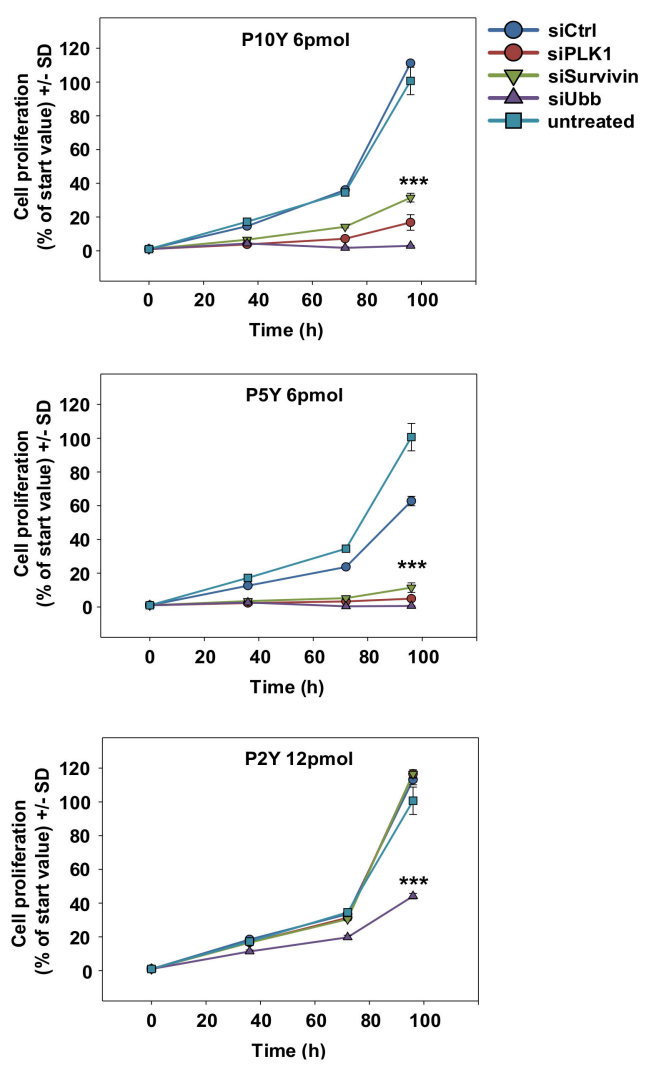

Figure 1. (A) Reaction scheme of tyrosine-coupling onto branched polyethylenimines (PEIs). Abbreviations: TFA, Trifluoroacetic acid; NHS, N-Hydroxysuccinimid; EDC, 1-Ethyl-3-(3dimethylaminopropyl) carbodiimid (B) Knockdown efficacies of various tyrosine-modified PEI/siRNA complexes in PC3 cells targeting the oncogenes polo-like kinase 1 (PLK1) (left) or survivin (right), quantitated by RT-qPCR. (C) Determination of anchorage-dependent proliferation of PC3 cells upon transfection with the tyrosine-modified PEI/siRNA complexes using different anti-proliferative siRNAs at the amounts indicated in the figures. SiRNA-mediated cell inhibition is compared to negative-control transfected or untreated cells. (D) Knockdown upon transfecting Saos-2 cells with siRNAs against PLK1 or survivin, as determined by RT-qPCR. Increasing mass ratios from 2.5 to 3.75 does not further improve the knockdown efficacy. (E) Determination of anchorage-dependent proliferation of Saos-2 cells upon transfection with P5Y/siRNA complexes targeting PLK1 or survivin. The statistical significance indicates the difference to negative-control transfected cells. Left: quantitation based on WST-8 measurements; right: original pictures.

To further analyze possible reasons for these observed differences in biological activity, we determined intracellular levels of fluorophore-labeled siRNAs upon transfection of PC3 cells complexed 
with the different tyrosine-modified PEIs. The comparison of P5Y/atto488-siRNA complexes with their P10Y counterparts used for transfection in the presence of fetal calf serum (FCS) revealed a $\sim 30 \%$ decrease in siRNA fluorescence when switching from P5Y to P10Y, while siRNA delivery in P2Y complexes was poor (Figure S3A). This was also confirmed in confocal microscopy, demonstrating atto488-siRNA signals to be largely absent upon transfection with P2Y (Figure S3B, upper panel). In contrast, profound fluorescence was observed in the case of P5Y and P10Y, with somewhat stronger signals in the case of P5Y/siRNA complexes (Figure S3B, center and lower panels). Beyond complex uptake, these differences may be based on variations in complex stabilities. Interestingly, a heparin displacement assay revealed even enhanced P5Y/siRNA complex stability in the presence vs. in the absence of serum, as indicated by the shift towards higher heparin concentrations required for siRNA release from the complex upon its pre-incubation in FCS (Figure S3C, upper panels). Under the same conditions, siRNA release from P2Y/siRNA complexes was already observed at lower heparin concentrations, indicating poor complex stability. In stark contrast, siRNA bands from heparin displacement of P10Y/siRNA complexes were weaker, independent of the heparin concentration, and thus indicating incomplete siRNA release even under very stringent conditions. Taken together, this suggests differences in siRNA delivery, complex stability, and siRNA release as underlying reasons for molecular weight-dependent differences between the tyrosine-modified PEIs. Very high efficacies of tyrosine-modified branched PEIs were observed up to as low as $5 \mathrm{kDa}$ (P5Y), while only an even further reduction of the molecular weight (P2Y) eventually led to reduced transfection efficacies. This prompted us to focus in particular on P5Y as the tyrosine-modified PEI with the lowest molecular weight and highest activity, which was even slightly above P10Y.

The very profound siRNA transfection efficacies of P5Y were also confirmed in other cell lines like Saos-2 osteosarcoma cells (Figure 1D). A 1.5-fold increase of the polymer/siRNA mass ratio did not lead to enhanced knockdown, indicating that the very low polymer/siRNA mass ratio of 2.5 was already sufficient for maximum complex activity (Figure 1D). In contrast, knockdown efficacies were found to be dependent on the selection of the siRNA and the target gene, as indicated by the particularly profound $>90 \%$ knockdown in the case of an siRNA targeting glyceraldehyde-3-phosphate dehydrogenase (GAPDH). As before in PC3 cells, an almost complete abolishment of cell proliferation was observed upon transfecting Saos-2 cells with P5Y/siPLK-1 or P5Y/siSurv complexes (Figure 1E). The microscopic evaluation of the wells also revealed a complete (siSurv) or almost complete (siPLK-1) loss of viable cells after $72 \mathrm{~h}$ (Figure 1E, right panel). In all experiments, P5Y-complexed negative control siRNA (siCtrl) was transfected in parallel, with the comparison to untransfected cells indicating non-specific transfection effects to be largely absent. As seen before in PC 3 cells, an increase in the polymer/siRNA ratio by 1.5-fold did not further enhance biological efficacies. However, the P5Y/siCtrl curve indicated some non-specific inhibitory effects at this ratio due to excess polymer (Figure S2B). Specific growth inhibition upon P5Y/siRNA-mediated survivin knockdown was also observed in MV3 melanoma cells (Figure S2C), and GAPDH target gene reduction similar to the results shown above were also found in other cell lines (H441 lung adenocarcinoma cells, PC3 prostate carcinoma cells, and G55T2 glioblastoma cells; Figure S2D).

\subsection{Characterization of P5Y/siRNA Complex Properties}

For physicochemical characterization, complexes with different polymer/siRNA mass ratios were subjected to Zetasizer and Nanosight measurements. The hydrodynamic diameters determined by dynamic light scattering (DLS) were around 200-400 nm, with a slight trend towards smaller complexes with lower P5Y/siRNA mass ratios (Figure 2A). 

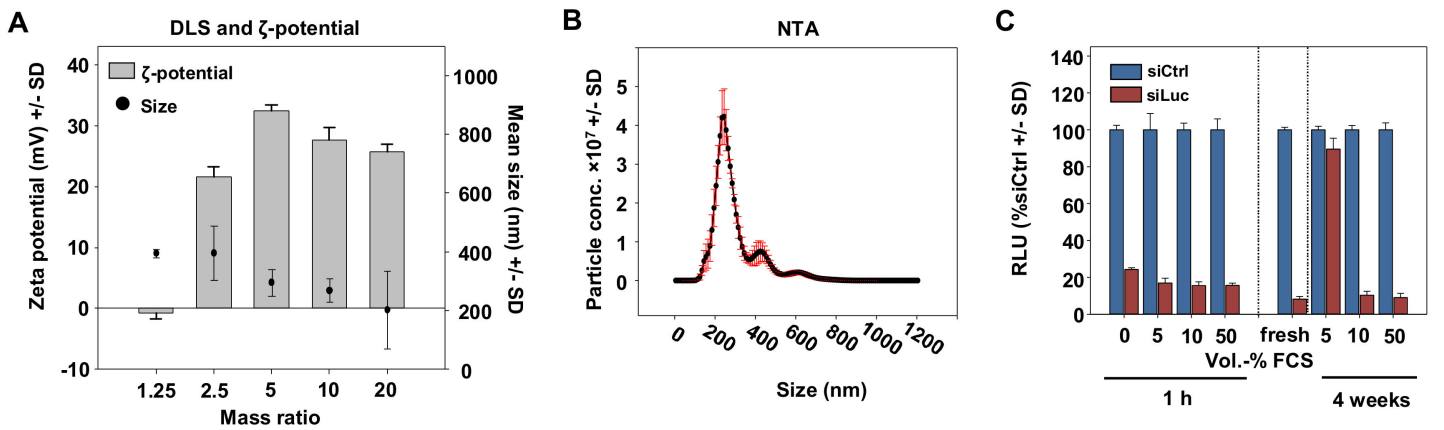

Figure 2. (A) Determination of the hydrodynamic diameters and zeta potentials of P5Y/siRNA complexes at different mass ratios as indicated in the figure. (B) Size measurement of P5Y/siRNA complexes by nanoparticle tracking (NTA) at the optimal mass ratio of 2.5. (C) Luciferase knockdown efficacies in H441-Luc cells for P5Y/siRNA complexes pre-incubated with increasing amounts of FCS $(v / v)$ prior to transfection for $1 \mathrm{~h}$ (left) or upon storage for 4 weeks at $4{ }^{\circ} \mathrm{C}$.

The diameter for the optimal mass ratio of 2.5 was additionally characterized by nanoparticle tracking (NTA) of which the main peak was at $200 \mathrm{~nm}$ and a second small peak at $400 \mathrm{~nm}$ (Figure 2B). The measurement of the zeta potentials revealed a slightly negative value for the lowest mass ratio of 1.25 indicating non complexed siRNA, and strongly increased to $+20 \mathrm{mV}$ for the mass ratio 2.5. The zeta potential further increased to $\sim 30 \mathrm{mV}$ at mass ratio 5 and reached a plateau of $\sim 25 \mathrm{mV}$ for mass ratios above 10. In many nanoparticle formulations, serum stability has been identified as one major issue limiting biological activity. Our transfection experiments, however, were exclusively performed in serum-containing media (10\% FCS). Moreover, the presence of serum even proved beneficial: While PEI-based complexes tend to readily aggregate in aqueous solutions [42], our P5Y/siRNA complexes could be stored over weeks in the presence of $10 \%$ or even $50 \%$ FCS without losing activity, while $5 \%$ FCS was insufficient (Figure 2C).

\subsection{High Biocompatibility/Absence of Toxicity of P5Y/siRNA Complexes}

High biological activity may well be associated with increased cytotoxicity or other adverse effects, which were therefore assessed next. Lactate dehydrogenase (LDH) release assays, however, revealed no increase of LDH levels over background (untransfected cells). This was true for both, P5Y/siRNA and P10Y/siRNA complexes and was found in two reporter cell lines (PC3-Luc-EGFP and G55T2-Luc-EGFP cells; Figure 3A,D).

Again, the transfection led to profound target gene knockdown, indicated by $80-90 \%$ decreased EGFP activities upon siEGFP transfection as determined in flow cytometry (Figure 3B,E). Concomitantly, cell viabilities remained unaffected by P5Y/siRNA or P10Y/siRNA transfection, even after $48 \mathrm{~h}$ and independent of siRNA amounts, which could be increased from 4 pmol to 12 pmol without appreciable decrease in metabolic activity (Figure 3C,F). In line with the absence of adverse effects on cell membrane integrity (LDH release assay), a hemoglobin release assay in erythrocytes revealed no adverse effects. Within an almost 10-fold range of different complex amounts, no hemoglobin release over background was observed (Figure 3G). Similarly, the P5Y/siRNA complexes were tested for their erythrocyte aggregation potential. Identical complex amounts were incubated with red blood cells and analyzed under the microscope (Figure 3H). While the positive control a $750 \mathrm{kDa}$ PEI led to strong aggregates at $1 \mu \mathrm{g}$, the P5Y complexes did not damage the red blood cells up to $3 \mu \mathrm{g}$ complexed siRNA. 
A

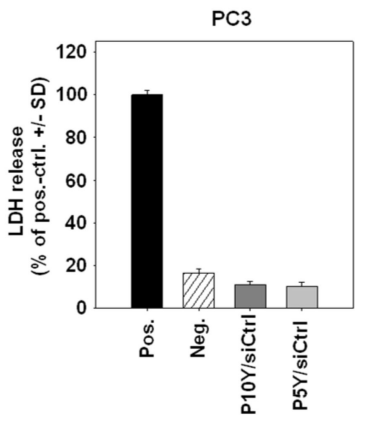

D

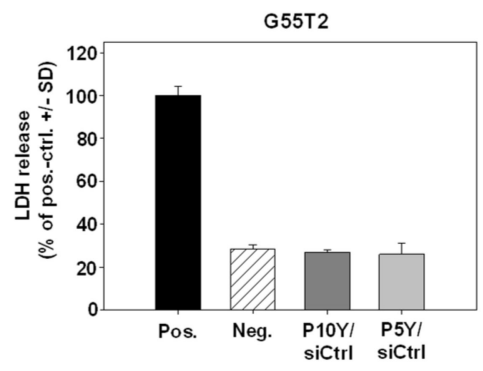

G

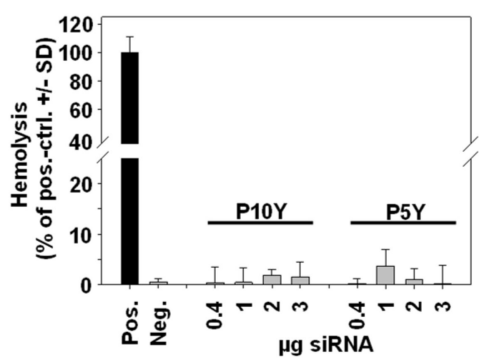

B

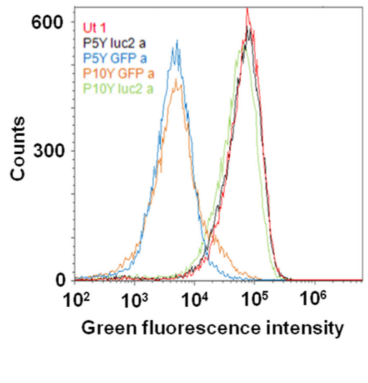

E

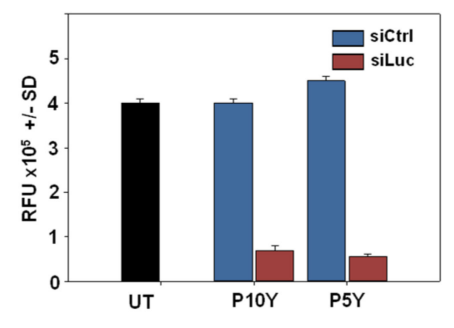

H

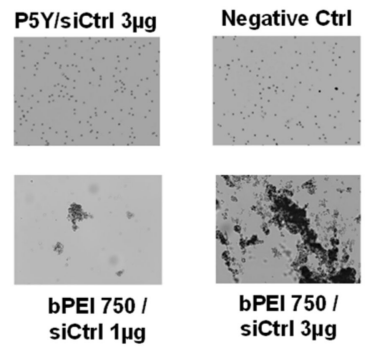

C

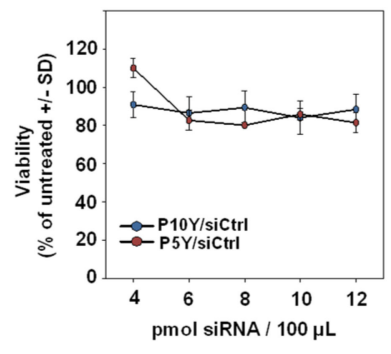

$\mathbf{F}$

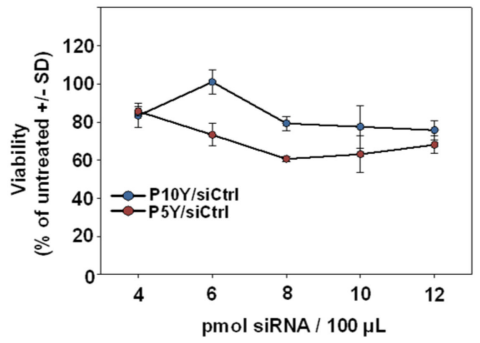

Figure 3. (A,D) Absence of early cytotoxic effects, as determined in lactate dehydrogenase (LDH) release assays for P10Y/siCtrl and P5Y/siCtrl complexes in PC3 (A) and G55T2 (D) cells. LDH release was quantitated $24 \mathrm{~h}$ after transfection of $30 \mathrm{pmol}$ siCtrl/polymer per 24 well. (B,E) Knockdown of the Enhanced Green Fluorescent Protein (EGFP) reporter gene in stably expressing PC3-EGFP/Luc (B) and G55T2-EGFP/Luc (E) cells. Cells were transfected with P10Y and P5Y siRNA complexes and analyzed after $72 \mathrm{~h}$ by flow cytometry. (C,F) Cell viabilities of PC3 cells (C) and G55T2 cells (F) $48 \mathrm{~h}$ after transfection of P10Y/siCtrl and P5Y/siCtrl complexes at mass ratio 2.5 with increasing siRNA-concentrations. (G) Hemolysis assay for P5Y/siRNA complexes, demonstrating the absence of erythrocyte damage over a wider range of different concentrations. (H) Erythrocyte aggregation assay, further confirming the biocompatibility of P5Y/siRNA complexes as shown for $3 \mu \mathrm{g}$ complexed siRNA (upper left; all lens magnifications: $4 \times$ ). A total of $750 \mathrm{kDa}$ bPEI complexes served as positive control, which led to a dose-dependent, profound aggregation of the red blood cells.

\subsection{Therapeutic In Vivo Application of P5Y/siRNA Complexes Leads to Profound Anti-Tumor Effects}

Pivotal in the development of nanoparticles for siRNA delivery is their applicability in vivo. In previous biodistribution assays, we showed that PEI/siRNA or P10Y/siRNA complexes become systemically available upon i.p. injection, and thus are able to reach organs/tissues remote from the injection site including tumors [50,55]. These studies were now extended towards P5Y/siRNA complexes. In a first experiment, P5Y/siRNA complexes were tested for reporter gene knockdown in mice bearing s.c. HCT116-Luc tumor xenografts. Prior to the in vivo application, the P5Y complexes were first evaluated in vitro for their potential to transfect this cell line. The luciferase expression was 
decreased to $60 \%$ at the lowest siRNA concentration of 15 pmol and further to $25 \%$ of control levels at 30 pmol siRNA (Figure 4A).

A

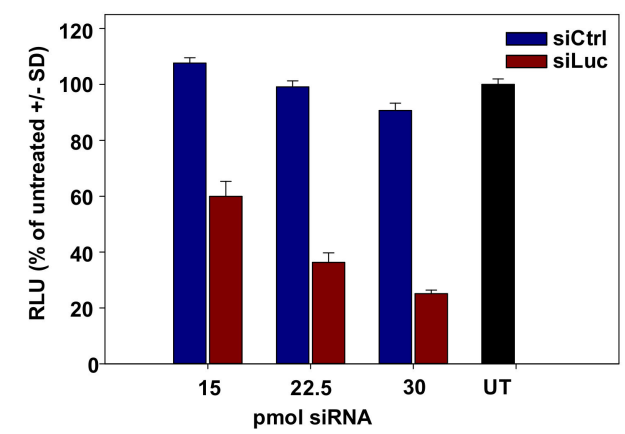

B

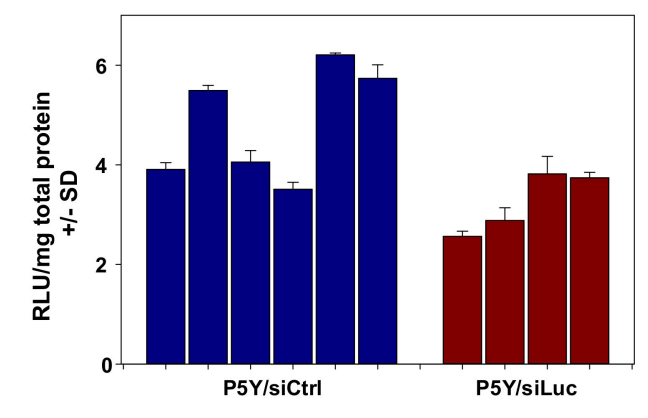

Figure 4. (A) Evaluation of luciferase knockdown efficacies of P5Y/siRNA complexes for in vivo use, in stably expressing HCT116-Luc cells over a range of different siRNA concentrations as indicated in the figure. (B) Luciferase activity of lysed HCT116-Luc tumors after in vivo treatment with P5Y/siRNA complexes. Bars represent the luciferase activities normalized for total protein concentrations from individual tumors of siCtrl-treated (blue) and siLuc-treated (red) mice.

Next, mice were injected with $5 \times 10^{6}$ tumor cells and, upon establishment of tumor xenografts, treated by repeated systemic application of $10 \mu \mathrm{g}$ P5Y-complexed siRNA ( $3 \times$ every second day, intraperitoneal injection). Upon termination of the experiment at day 6 after treatment start, tumors were harvested and luciferase activities were analyzed from tumor lysates. Some variations were found between individual samples, especially in the negative control group. Still, the comparison of luciferase activities between the specific (P5Y/siLuc3) and the non-specific negative control (P5Y/siCtrl) group revealed a $\sim 25 \%$ reduction of luciferase expression already after three injections (Figure $4 \mathrm{~B}$ ), and thus confirm that the treatment of mice with P5Y/siRNA complexes leads indeed to the knockdown of a given target gene in the tumors.

Switching to a more relevant therapy model, PC3 cells were s.c. injected into mice. Upon establishment of tumor xenografts of $\sim 100 \mathrm{~mm}^{3}$ in size and with clear growth kinetics, mice were randomized into different groups. Specific treatment relied on the P5Y-complexed siRNAs targeting the oncogenic proteins PLK-1 or survivin. For P10Y complexation, only PLK1 was selected as specific siRNA, while untreated mice or mice treated with siCtrl-containing complexes served as negative controls. The comparison of the latter groups revealed the absence of non-specific effects of repeated treatments ( $3 \times /$ week), as indicated by identical tumor growth curves (Figure 5A,B). In contrast, the treatment with the P5Y/siPLK-1 or P5Y/siSurv (Figure 5A) or P10Y/siSurv complexes (Figure 5B) led to profound antitumor effects.

During the experiment and upon its termination, mice were also screened and tested for possible adverse effects due to the repeated i.p. administration of P5Y/siRNA complexes. Mice showed no alterations in behavior, no obvious weight loss, and no other signs of adverse effects. In addition, possible toxic effects were determined by measuring important serum parameters. Healthy mice were repeatedly i.p. injected with P5Y complexes comprising $10 \mu \mathrm{g}$ siCtrl four times over eight days. The serum analyses revealed no increase in liver enzymes (ASAT, ALAT), blood glucose (Gluc), urea, albumin, or LDH (Figure 6A). Other side effects may include the unwanted stimulation of the innate immune system. To test for this, immunocompetent mice were treated twice within $24 \mathrm{~h}$ with P5Y/siCtrl complexes. In this experiment, i.v. injection was preferred over i.p. administration to achieve instantaneous $100 \%$ bioavailability, and serum levels were analyzed at $4 \mathrm{~h}$ after the last injection, as described previously [50]. As shown in Figure 6B, no increase in TNF $\alpha$ or IFN $\gamma$ levels were observed. We thus conclude that P5Y/siRNA complexes are efficient and safe in vitro and in vivo. 
A
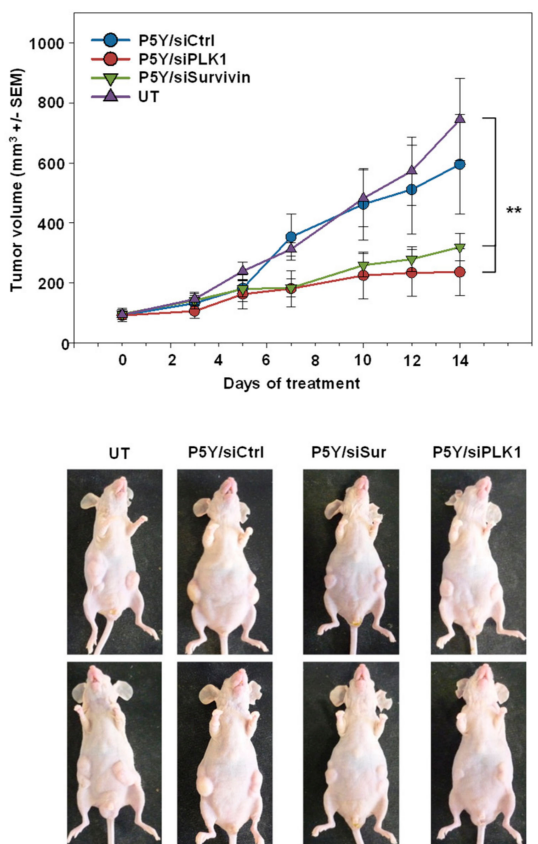
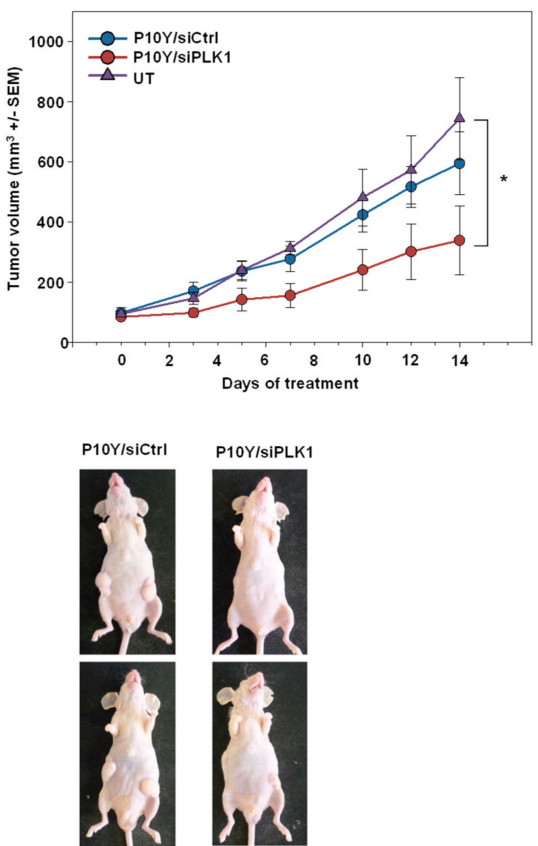

Figure 5. Therapy studies in PC3 tumor bearing mice using P5Y/siRNA (A) or P10Y/siRNA (B) complexes targeting either the oncogenes PLK1 or survivin. Mice were intraperitoneally treated with the complexes equivalent to $10 \mu \mathrm{g}$ siRNA every 2-3 days. Tumor growth curves (upper panels) demonstrate the growth inhibiting effects of the specifically treated groups as compared to a negative control treated or untreated group. Lower panels: representative examples of mice.

A

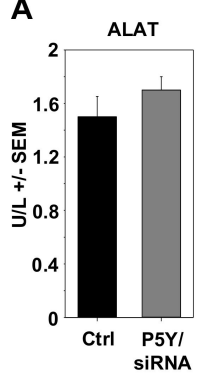

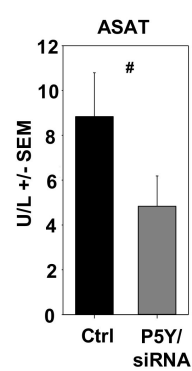
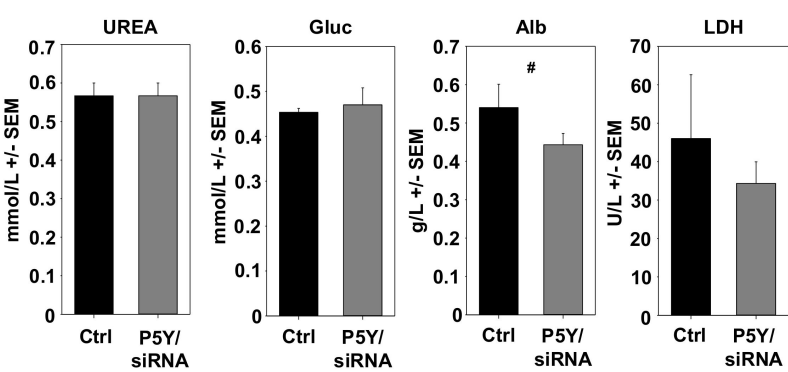

B
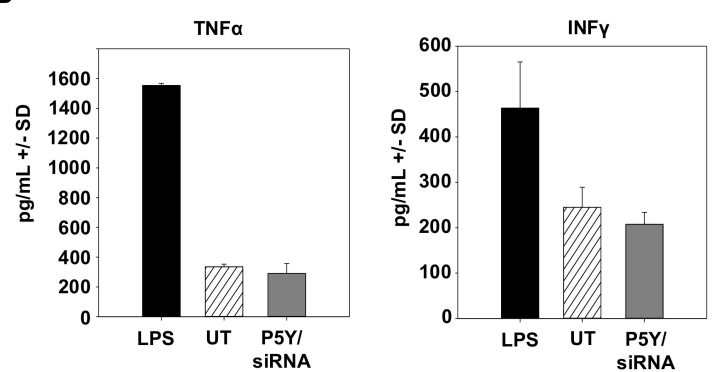

Figure 6. (A) Determination of blood serum markers for hepatotoxicity, cardiac or skeletal muscle damage, and kidney dysfunction. Healthy mice were repeatedly i.p. injected with P5Y/siCtrl complexes and blood serum levels were compared to untreated mice. ALAT: Alanine aminotransferase; ASAT: Aspartate aminotransferase; Gluc: Glucose; Alb: Albumin; LDH: Lactate deghydrogenase. (B) Absence of immunostimulation of P5Y/siCtrl complexes. Complexes were i.v. injected into immunocompetent mice twice within $24 \mathrm{~h}$ and blood was collected $4 \mathrm{~h}$ after the last injection. Treatment with lipopolysaccharides (LPS) served as positive control. \#, not significant. 


\section{Discussion}

PEIs and other cationic polymers are promising with regard to nucleic acid delivery, but they are often associated with toxicity. This is particularly true for higher molecular weight PEIs, while their lower molecular weight counterparts suffer from poor efficacy [21-23]. The toxicity of high molecular weight PEIs occurs at later stages. An early toxic effect is largely due to a disturbance of the cell membrane after contact with the complexes, leading to increased LDH release and induction of necrosis [56]. The late-stage cytotoxicity was reported to be caused by a damage of the mitochondrial membrane and subsequent activation of caspases and cytochrome $C$ release [57-59]. While the latter findings have been frequently reported, the genotoxic potential of PEI is controversially discussed. Both, the presence and absence of DNA-damaging potential has been reported [60-63] and, possibly explaining these discrepancies, may be dependent on the tested concentrations and selected cell lines.

The fact that PEIs offer relatively easy access to chemical modification is a particularly attractive approach for further improvement of physicochemical and biological properties of the polymer and its complexes. Tyrosine may be considered as among the best candidate amino acids for chemical modification, due to its ability to balance between hydrophilicity (primary amines necessary for nucleic acid complexation) and hydrophobicity (favoring cellular internalization and endosomal escape [44,46]). Many chemical modifications of low molecular weight PEIs in order to increase their bioactivity rely on the cross-linking to create larger PEI derivatives, the coupling of lipidic groups to facilitate micellar structures for improved nucleic acid binding, or modifications with cationic groups to increase the electrostatic interactions (see Introduction). The aromatic amino acid tyrosine plays a key role in protein/DNA interactions. Several studies have reported that tyrosine is essential for the binding to nucleic acids by hydrogen bonding and by $\pi-\pi$-stacking $[64,65]$, which can provide an explanation for the substantial increase in very low molecular weight PEI bioactivity upon tyrosine modification. Generally, phenol-containing molecules are an interesting motif to positively affect a given nucleic acid delivery system. For example, the pre-incubation of siRNA with EGCG, a polyphenol from green tea, and subsequent complexation with low molecular weight polyamines $\leq 5 \mathrm{kDa}$ (PEI, PLL, PAMAM) strongly increased the knockdown efficacy [22].

Serum stability is an important factor for nucleic acid delivery systems, and we demonstrate high serum compatibility of our complexes based on tyrosine-modified PEIs (see Results and [50]). This may be attributed to the hydroxyl group of tyrosine. In contrast to phenylalanine, tyrosine shows negligible interactions with bovine serum albumin (BSA), as shown previously by the incubation of thymine-dityrosine or thymine-diphenylalanine with BSA solutions [66]. Still, P5Y/siRNA complex stability was even slightly enhanced upon incubation in serum (see Figure S3C). The stabilizing effect of hydroxyl groups was demonstrated in another study, by the modification of PEI with a hydroxyl-containing cyclic carbonate (EHDO). This modification improved serum-tolerance and reduced cytotoxicity as compared to the parent $25 \mathrm{kDa}$ bPEI [67]. Similar results were reported for the Tris-modification of $25 \mathrm{kDa}$ bPEI for pDNA and siRNA delivery [68].

Indeed, we could demonstrate in this study that tyrosine-modification allows for using very low, otherwise inactive PEIs. High complexation efficacies even at very low mass ratios are particularly relevant in the case of small oligonucleotides like siRNAs, considering the lack of binding cooperativity and their high rigidity [69]. Our results are in line with other studies demonstrating low toxicity and high biocompatibility of other (non-PEI) tyrosine-based polymers [70], as well as the safety of tyrosine in humans [71]. The beneficial effects of tyrosine modification thus allowed for using very small amounts of (derivatized) non-toxic low molecular weight PEIs whose bioactivity and biocompatibility critically relies on the grafting with tyrosine. Optimal complex stabilities, which need to be sufficiently high for efficient siRNA complexation/protection and sufficiently low for efficient intracellular siRNA release from the complex, are additional requirements. The potential relevance of the approach of using tyrosine-modified PEIs for translation into the clinic is emphasized by the fact that these nanoparticles were found to be efficacious also in vivo. 
Supplementary Materials: The following are available online at http://www.mdpi.com/1999-4923/11/11/600/s1, Figure S1: Degrees of tyrosine grafting and original ${ }^{1} \mathrm{H}-\mathrm{NMR}$ spectra, Figure S2: Additional data to Figure 1, Figure S3A,B: Cellular siRNA uptake, Figure S3C: complex stabilities, Table S1: siRNA sequences, Table S2: RT-qPCR primer sequences.

Author Contributions: Conceptualization, A.E. and A.A.; methodology, A.E., S.N., and M.K.; investigation, A.E., S.N., and M.K.; writing - original draft preparation, A.E. and A.A.; writing-review and editing, A.E. and A.A.; supervision, A.A.; project administration, A.A.; funding acquisition, A.A.

Funding: This research was funded by the Deutsche Forschungsgemeinschaft (DFG), grant number AI 24/21-1, and the Deutsche Krebshilfe (grant number 111616) to A.A.

Acknowledgments: The authors are grateful to Markus Böhlmann and Anne-Kathrin Krause for expert mouse maintenance, the core unit "fluorescence technologies" (Kathrin Jäger) for cell sorting and Gabi Oehme for technical assistance in tissue culture experiments. Aileen Heinze is acknowledged for proofreading the manuscript.

Conflicts of Interest: The authors declare no conflict of interest.

\section{References}

1. Fire, A.; Xu, S.; Montgomery, M.K.; Kostas, S.A.; Driver, S.E.; Mello, C.C. Potent and specific genetic interference by double-stranded RNA in Caenorhabditis elegans. Nature 1998, 391, 806-811. [CrossRef] [PubMed]

2. Setten, R.L.; Rossi, J.J.; Han, S.P. The current state and future directions of RNAi-based therapeutics. Nat. Rev. 2019, 18, 421-446. [CrossRef] [PubMed]

3. Bartlett, D.W.; Davis, M.E. Insights into the kinetics of siRNA-mediated gene silencing from live-cell and live-animal bioluminescent imaging. Nucleic Acids Res. 2006, 34, 322-333. [CrossRef] [PubMed]

4. Dahlman, J.E.; Barnes, C.; Khan, O.; Thiriot, A.; Jhunjunwala, S.; Shaw, T.E.; Xing, Y.; Sager, H.B.; Sahay, G.; Speciner, L.; et al. In vivo endothelial siRNA delivery using polymeric nanoparticles with low molecular weight. Nat. Nanotechnol. 2014, 9, 648-655. [CrossRef]

5. Whitehead, K.A.; Langer, R.; Anderson, D.G. Knocking down barriers: advances in siRNA delivery. Nat. Rev. 2009, 8, 129-138.

6. Khvorova, A.; Watts, J.K. The chemical evolution of oligonucleotide therapies of clinical utility. Nat. Biotechnol. 2017, 35, 238-248. [CrossRef]

7. Miele, E.; Spinelli, G.P.; Miele, E.; Di Fabrizio, E.; Ferretti, E.; Tomao, S.; Gulino, A. Nanoparticle-based delivery of small interfering RNA: challenges for cancer therapy. Int. J. Nanomed. 2012, 7, 3637-3657.

8. Basarkar, A.; Singh, J. Nanoparticulate systems for polynucleotide delivery. Int. J. Nanomed. 2007, 2, 353-360.

9. Merdan, T.; Kopecek, J.; Kissel, T. Prospects for cationic polymers in gene and oligonucleotide therapy against cancer. Adv. Drug Deliv. Rev. 2002, 54, 715-758. [CrossRef]

10. Ojea-Jimenez, I.; Tort, O.; Lorenzo, J.; Puntes, V.F. Engineered nonviral nanocarriers for intracellular gene delivery applications. Biomed. Mater. 2012, 7, 054106. [CrossRef]

11. Balazs, D.A.; Godbey, W. Liposomes for use in gene delivery. J. Drug Deliv. 2011, 2011, 326497. [CrossRef] [PubMed]

12. Zhi, D.; Zhang, S.; Cui, S.; Zhao, Y.; Wang, Y.; Zhao, D. The headgroup evolution of cationic lipids for gene delivery. Bioconjug. Chem. 2013, 24, 487-519. [CrossRef] [PubMed]

13. Jensen, K.; Anderson, J.A.; Glass, E.J. Comparison of small interfering RNA (siRNA) delivery into bovine monocyte-derived macrophages by transfection and electroporation. Vet. Immunol. Immunopathol. 2014, 158, 224-232. [CrossRef] [PubMed]

14. Hu, B.; Weng, Y.; Xia, X.H.; Liang, X.J.; Huang, Y. Clinical advances of siRNA therapeutics. J. Gene Med. 2019, 21, e3097. [CrossRef]

15. Adams, D.; Gonzalez-Duarte, A.; O’Riordan, W.D.; Yang, C.C.; Ueda, M.; Kristen, A.V.; Tournev, I.; Schmidt, H.H.; Coelho, T.; Berk, J.L.; et al. Patisiran, an RNAi Therapeutic, for Hereditary Transthyretin Amyloidosis. N. Engl. J. Med. 2018, 379, 11-21. [CrossRef]

16. Lorenzer, C.; Dirin, M.; Winkler, A.M.; Baumann, V.; Winkler, J. Going beyond the liver: progress and challenges of targeted delivery of siRNA therapeutics. J. Control. Release 2015, 203, 1-15. [CrossRef]

17. Ulkoski, D.; Bak, A.; Wilson, J.T.; Krishnamurthy, V.R. Recent advances in polymeric materials for the delivery of RNA therapeutics. Expert Opin. Drug Deliv. 2019, 16, 1149-1167. [CrossRef] 
18. Peng, L.; Wagner, E. Polymeric Carriers for Nucleic Acid Delivery: Current Designs and Future Directions. Biomacromolecules 2019, 20, 3613-3626. [CrossRef]

19. Hobel, S.; Aigner, A. Polyethylenimines for siRNA and miRNA delivery in vivo. Wiley Interdiscip. Reviews. Nanomed. Nanobiotechnol. 2013, 5, 484-501. [CrossRef]

20. Pandey, A.P.; Sawant, K.K. Polyethylenimine: A versatile, multifunctional non-viral vector for nucleic acid delivery. Mater. Sci. Eng. Cmaterials Biol. Appl. 2016, 68, 904-918. [CrossRef]

21. Kwok, A.; Hart, S.L. Comparative structural and functional studies of nanoparticle formulations for DNA and siRNA delivery. Nanomed. Nanotechnol. Biol. Med. 2011, 7, 210-219. [CrossRef] [PubMed]

22. Shen, W.; Wang, Q.; Shen, Y.; Gao, X.; Li, L.; Yan, Y.; Wang, H.; Cheng, Y. Green Tea Catechin Dramatically Promotes RNAi Mediated by Low-Molecular-Weight Polymers. ACS Cent. Sci. 2018, 4, 1326-1333. [CrossRef] [PubMed]

23. Shim, M.S.; Kwon, Y.J. Acid-responsive linear polyethylenimine for efficient, specific, and biocompatible siRNA delivery. Bioconjug. Chem. 2009, 20, 488-499. [CrossRef] [PubMed]

24. Werth, S.; Urban-Klein, B.; Dai, L.; Hobel, S.; Grzelinski, M.; Bakowsky, U.; Czubayko, F.; Aigner, A. A low molecular weight fraction of polyethylenimine (PEI) displays increased transfection efficiency of DNA and siRNA in fresh or lyophilized complexes. J. Control. Release 2006, 112, 257-270. [CrossRef] [PubMed]

25. Williford, J.M.; Archang, M.M.; Minn, I.; Ren, Y.; Wo, M.; Vandermark, J.; Fisher, P.B.; Pomper, M.G.; Mao, H.Q. Critical Length of PEG Grafts on 1PEI/DNA Nanoparticles for Efficient in Vivo Delivery. ACS Biomater. Sci. Eng. 2016, 2, 567-578. [CrossRef] [PubMed]

26. Malek, A.; Czubayko, F.; Aigner, A. PEG grafting of polyethylenimine (PEI) exerts different effects on DNA transfection and siRNA-induced gene targeting efficacy. J. Drug Target. 2008, 16, 124-139. [CrossRef]

27. Malek, A.; Merkel, O.; Fink, L.; Czubayko, F.; Kissel, T.; Aigner, A. In vivo pharmacokinetics, tissue distribution and underlying mechanisms of various PEI(-PEG)/siRNA complexes. Toxicol. Appl. Pharmacol. 2009, 236, 97-108. [CrossRef]

28. Li, S.; Wang, Y.; Zhang, J.; Yang, W.H.; Dai, Z.H.; Zhu, W.; Yu, X.Q. Biodegradable cross-linked poly(amino alcohol esters) based on LMW PEI for gene delivery. Mol. Biosyst. 2011, 7, 1254-1262. [CrossRef]

29. Wang, C.; Yuan, W.; Xiao, F.; Gan, Y.; Zhao, X.; Zhai, Z.; Zhao, X.; Zhao, C.; Cui, P.; Jin, T.; et al. Biscarbamate Cross-Linked Low-Molecular-Weight Polyethylenimine for Delivering Anti-chordin siRNA into Human Mesenchymal Stem Cells for Improving Bone Regeneration. Front. Pharmacol. 2017, 8, 572. [CrossRef]

30. Bonner, D.K.; Zhao, X.; Buss, H.; Langer, R.; Hammond, P.T. Crosslinked linear polyethylenimine enhances delivery of DNA to the cytoplasm. J. Control. Release 2013, 167, 101-107. [CrossRef]

31. Breunig, M.; Hozsa, C.; Lungwitz, U.; Watanabe, K.; Umeda, I.; Kato, H.; Goepferich, A. Mechanistic investigation of poly(ethylene imine)-based siRNA delivery: disulfide bonds boost intracellular release of the cargo. J. Control. Release 2008, 130, 57-63. [CrossRef] [PubMed]

32. Jiang, H.L.; Islam, M.A.; Xing, L.; Firdous, J.; Cao, W.; He, Y.J.; Zhu, Y.; Cho, K.H.; Li, H.S.; Cho, C.S. Degradable Polyethylenimine-Based Gene Carriers for Cancer Therapy. Top. Curr. Chem. 2017, 375, 34. [CrossRef] [PubMed]

33. Feldmann, D.P.; Xie, Y.; Jones, S.K.; Yu, D.; Moszczynska, A.; Merkel, O.M. The impact of microfluidic mixing of triblock micelleplexes on in vitro / in vivo gene silencing and intracellular trafficking. Nanotechnology 2017, 28, 224001. [CrossRef]

34. Goyal, R.; Tripathi, S.K.; Vazquez, E.; Kumar, P.; Gupta, K.C. Biodegradable poly(vinyl alcohol)-polyethylenimine nanocomposites for enhanced gene expression invitro and invivo. Biomacromolecules 2012, 13, 73-83. [CrossRef] [PubMed]

35. Yamada, H.; Loretz, B.; Lehr, C.M. Design of starch-graft-PEI polymers: an effective and biodegradable gene delivery platform. Biomacromolecules 2014, 15, 1753-1761. [CrossRef] [PubMed]

36. Wu, P.; Luo, X.; Wu, H.; Yu, F.; Wang, K.; Sun, M.; Oupicky, D. Cholesterol Modification Enhances Antimetastatic Activity and siRNA Delivery Efficacy of Poly(ethylenimine)-Based CXCR4 Antagonists. Macromol. Biosci. 2018, 18, e1800234. [CrossRef] [PubMed]

37. Khan, O.F.; Kowalski, P.S.; Doloff, J.C.; Tsosie, J.K.; Bakthavatchalu, V.; Winn, C.B.; Haupt, J.; Jamiel, M.; Langer, R.; Anderson, D.G. Endothelial siRNA delivery in nonhuman primates using ionizable low-molecular weight polymeric nanoparticles. Sci. Adv. 2018, 4, eaar8409. [CrossRef] 
38. Thapa, B.; Plianwong, S.; Remant Bahadur, K.C.; Rutherford, B.; Uludag, H. Small hydrophobe substitution on polyethylenimine for plasmid DNA delivery: Optimal substitution is critical for effective delivery. Acta Biomater. 2016, 33, 213-224. [CrossRef]

39. Schafer, J.; Hobel, S.; Bakowsky, U.; Aigner, A. Liposome-polyethylenimine complexes for enhanced DNA and siRNA delivery. Biomaterials 2010, 31, 6892-6900. [CrossRef]

40. Ewe, A.; Aigner, A. Nebulization of liposome-polyethylenimine complexes (lipopolyplexes) for DNA or siRNA delivery: Physicochemical properties and biological activity. Eur. J. Lipid Sci. Technol. 2014, 116, 1195-1204. [CrossRef]

41. Ewe, A.; Panchal, O.; Pinnapireddy, S.R.; Bakowsky, U.; Przybylski, S.; Temme, A.; Aigner, A. Liposome-polyethylenimine complexes (DPPC-PEI lipopolyplexes) for therapeutic siRNA delivery in vivo. Nanomed. Nanotechnol. Biol. Med. 2016, 13, 209-218. [CrossRef] [PubMed]

42. Ewe, A.; Schaper, A.; Barnert, S.; Schubert, R.; Temme, A.; Bakowsky, U.; Aigner, A. Storage stability of optimal liposome-polyethylenimine complexes (lipopolyplexes) for DNA or siRNA delivery. Acta Biomater. 2014, 10, 2663-2673. [CrossRef] [PubMed]

43. Navath, R.S.; Menjoge, A.R.; Wang, B.; Romero, R.; Kannan, S.; Kannan, R.M. Amino acid-functionalized dendrimers with heterobifunctional chemoselective peripheral groups for drug delivery applications. Biomacromolecules 2010, 11, 1544-1563. [CrossRef] [PubMed]

44. Wang, F.; Hu, K.; Cheng, Y. Structure-activity relationship of dendrimers engineered with twenty common amino acids in gene delivery. Acta Biomater. 2016, 29, 94-102. [CrossRef] [PubMed]

45. Wang, F.; Wang, Y.; Wang, H.; Shao, N.; Chen, Y.; Cheng, Y. Synergistic effect of amino acids modified on dendrimer surface in gene delivery. Biomaterials 2014, 35, 9187-9198. [CrossRef]

46. Creusat, G.; Zuber, G. Self-assembling polyethylenimine derivatives mediate efficient siRNA delivery in mammalian cells. Chembiochem A Eur. J. Chem. Biol. 2008, 9, 2787-2789. [CrossRef]

47. Yu, W.; Zheng, Y.; Yang, Z.; Fei, H.; Wang, Y.; Hou, X.; Sun, X.; Shen, Y. N-AC-1-Leu-PEI-mediated miR-34a delivery improves osteogenic differentiation under orthodontic force. Oncotarget 2017, 8, 110460-110473. [CrossRef]

48. He, D.; Muller, K.; Krhac Levacic, A.; Kos, P.; Lachelt, U.; Wagner, E. Combinatorial Optimization of Sequence-Defined Oligo(ethanamino)amides for Folate Receptor-Targeted pDNA and siRNA Delivery. Bioconjug. Chem 2016, 27, 647-659. [CrossRef]

49. Lee, D.J.; He, D.; Kessel, E.; Padari, K.; Kempter, S.; Lachelt, U.; Radler, J.O.; Pooga, M.; Wagner, E. Tumoral gene silencing by receptor-targeted combinatorial siRNA polyplexes. J. Control. Release 2016, 244, 280-291. [CrossRef]

50. Ewe, A.; Przybylski, S.; Burkhardt, J.; Janke, A.; Appelhans, D.; Aigner, A. A novel tyrosine-modified low molecular weight polyethylenimine (P10Y) for efficient siRNA delivery in vitro and in vivo. J. Control. Release 2016, 230, 13-25. [CrossRef]

51. Ewe, A.; Hobel, S.; Heine, C.; Merz, L.; Kallendrusch, S.; Bechmann, I.; Merz, F.; Franke, H.; Aigner, A. Optimized polyethylenimine (PEI)-based nanoparticles for siRNA delivery, analyzed in vitro and in an ex vivo tumor tissue slice culture model. Drug Deliv. Transl. Res. 2017, 7, 206-216. [CrossRef] [PubMed]

52. Beegle, J.; Lakatos, K.; Kalomoiris, S.; Stewart, H.; Isseroff, R.R.; Nolta, J.A.; Fierro, F.A. Hypoxic preconditioning of mesenchymal stromal cells induces metabolic changes, enhances survival, and promotes cell retention in vivo. Stem. Cells 2015, 33, 1818-1828. [CrossRef] [PubMed]

53. Campeau, E.; Ruhl, V.E.; Rodier, F.; Smith, C.L.; Rahmberg, B.L.; Fuss, J.O.; Campisi, J.; Yaswen, P.; Cooper, P.K.; Kaufman, P.D. A versatile viral system for expression and depletion of proteins in mammalian cells. PLoS ONE 2009, 4, e6529. [CrossRef] [PubMed]

54. Livak, K.J.; Schmittgen, T.D. Analysis of relative gene expression data using real-time quantitative PCR and the 2(-Delta Delta C(T)) Method. Methods 2001, 25, 402-408. [CrossRef]

55. Hobel, S.; Koburger, I.; John, M.; Czubayko, F.; Hadwiger, P.; Vornlocher, H.P.; Aigner, A. Polyethylenimine/small interfering RNA-mediated knockdown of vascular endothelial growth factor in vivo exerts anti-tumor effects synergistically with Bevacizumab. J. Gene Med. 2010, 12, 287-300.

56. Moghimi, S.M.; Symonds, P.; Murray, J.C.; Hunter, A.C.; Debska, G.; Szewczyk, A. A two-stage poly(ethylenimine)-mediated cytotoxicity: implications for gene transfer/therapy. Mol. Ther. 2005, 11, 990-995. [CrossRef] 
57. Monnery, B.D.; Wright, M.; Cavill, R.; Hoogenboom, R.; Shaunak, S.; Steinke, J.H.G.; Thanou, M. Cytotoxicity of polycations: Relationship of molecular weight and the hydrolytic theory of the mechanism of toxicity. Int. J. Pharm. 2017, 521, 249-258. [CrossRef]

58. Hall, A.; Larsen, A.K.; Parhamifar, L.; Meyle, K.D.; Wu, L.P.; Moghimi, S.M. High resolution respirometry analysis of polyethylenimine-mediated mitochondrial energy crisis and cellular stress: Mitochondrial proton leak and inhibition of the electron transport system. Biochim. Biophys. Acta 2013, 1827, 1213-1225. [CrossRef]

59. Yamamoto, T.; Tsunoda, M.; Ozono, M.; Watanabe, A.; Kotake, K.; Hiroshima, Y.; Yamada, A.; Terada, H.; Shinohara, Y. Polyethyleneimine renders mitochondrial membranes permeable by interacting with negatively charged phospholipids in them. Arch. Biochem. Biophys. 2018, 652, 9-17. [CrossRef]

60. Gholami, L.; Sadeghnia, H.R.; Darroudi, M.; Kazemi Oskuee, R. Evaluation of genotoxicity and cytotoxicity induced by different molecular weights of polyethylenimine/DNA nanoparticles. Turk. J. Biol. 2014, 38, 380-387. [CrossRef]

61. Castan, L.; Jose da Silva, C.; Ferreira Molina, E.; Alves Dos Santos, R. Comparative study of cytotoxicity and genotoxicity of commercial Jeffamines(R) and polyethylenimine in CHO-K1 cells. J. Biomed. Mater. Research. Part. Bapplied Biomater. 2018, 106, 742-750. [CrossRef] [PubMed]

62. Beyerle, A.; Long, A.S.; White, P.A.; Kissel, T.; Stoeger, T. Poly(ethylene imine) nanocarriers do not induce mutations nor oxidative DNA damage in vitro in MutaMouse FE1 cells. Mol. Pharm. 2011, 8, 976-981. [CrossRef] [PubMed]

63. Hall, A.; Lachelt, U.; Bartek, J.; Wagner, E.; Moghimi, S.M. Polyplex Evolution: Understanding Biology, Optimizing Performance. Mol. Ther. 2017, 25, 1476-1490. [CrossRef] [PubMed]

64. Plyte, S.E.; Kneale, G.G. The role of tyrosine residues in the DNA-binding site of the Pf1 gene 5 protein. Protein Eng. 1991, 4, 553-560. [CrossRef]

65. Huang, J.; Zhao, Y.; Liu, H.; Huang, D.; Cheng, X.; Zhao, W.; Taylor, I.A.; Liu, J.; Peng, Y.L. Substitution of tryptophan 89 with tyrosine switches the DNA binding mode of PC4. Sci. Rep. 2015, 5, 8789. [CrossRef]

66. Roviello, G.N.; Oliviero, G.; Di Napoli, A.; Borbone, N.; Piccialli, G. Synthesis, self-assembly-behavior and biomolecular recognition properties of thyminyl dipeptides. Arab J. Chem 2018. [CrossRef]

67. Luo, X.H.; Huang, F.W.; Qin, S.Y.; Wang, H.F.; Feng, J.; Zhang, X.Z.; Zhuo, R.X. A strategy to improve serum-tolerant transfection activity of polycation vectors by surface hydroxylation. Biomaterials 2011, 32, 9925-9939. [CrossRef]

68. Dong, X.; Lin, L.; Chen, J.; Guo, Z.; Tian, H.; Li, Y.; Wei, Y.; Chen, X. A serum-tolerant hydroxyl-modified polyethylenimine as versatile carriers of pDNA/siRNA. Macromol. Biosci. 2013, 13, 512-522. [CrossRef]

69. Bolcato-Bellemin, A.L.; Bonnet, M.E.; Creusat, G.; Erbacher, P.; Behr, J.P. Sticky overhangs enhance siRNA-mediated gene silencing. Proc. Natl. Acad. Sci. USA 2007, 104, 16050-16055. [CrossRef]

70. Bourke, S.L.; Kohn, J. Polymers derived from the amino acid L-tyrosine: polycarbonates, polyarylates and copolymers with poly(ethylene glycol). Adv. Drug Deliv. Rev. 2003, 55, 447-466. [CrossRef]

71. Baldrick, P.; Richardson, D.; Wheeler, A.W. Review of L-tyrosine confirming its safe human use as an adjuvant. J. Appl. Toxicol. Jat 2002, 22, 333-344. [CrossRef] [PubMed]

(C) 2019 by the authors. Licensee MDPI, Basel, Switzerland. This article is an open access article distributed under the terms and conditions of the Creative Commons Attribution (CC BY) license (http://creativecommons.org/licenses/by/4.0/). 